\title{
Studies on Antibacterial Activity of Some Medicinal Plants of Lonar Lake Forest in Maharashtra
}

\author{
Vinayak Rathod
}

\begin{abstract}
Alkaline Lonar Lake, located in the Buldhana district of Maharashtra State.India is the only hypervelocity meteotric impact Lonar Lake in basalt rock, ranking third in the world.Lonar Lake is surrounded by dense forest Costituting many Plants with high medicinal values. Because of the high alkalinity and diverse atmospheric conditions we have selected the area of the Lonar lake forest for determining the various uses of for the treatment of enteric infection available at Lonar Lake forest.The plants used for the study were justicia adhatada,Calotropis gigantean against some enteric infections. These two plants used for treatment of various enteric infections justicia adhatada,leaves is used in the nasal infection cough,Throat infection and Calotropis gigantean plant Leaves use in the boils, Elephantiasis, in wounds..According to the findings, it was concluded that all the economically affordable easily available selected two medicinal plants of Lonar Lake forest. These two Medicinal plants would serve,as effective against to reduce common health problems without causing any adverse reactions and side effects. .These plants are important source of potentially useful structures for the development of new chemotherapeutic agents.Medicinal plants have been traditionally used for different kinds of ailments including infections diseases. There is an increasing need for substances with the treatment of enteric infections with the available drugs often leads to the problem of disease resistance.In the present study the Ethanoal of leaf extracts of justicia adhatada,Calotropis and gigantean showed significant antimicrobial activity against $S$. aureus and E.coli The filter paper disc method was used for screening of crude ethanolic extract of leaves for antimicrobial activity. The paper discs saturated with extract were placed on the surface of the sterilized nutrient agar medium that had been inoculated with the test organism by using a sterile swab.The diameters of microbial inhibition zones were measured after 24 hours of incubation at $37^{\circ} \mathrm{C}$. According to the methodology used, it was possible to conclude that the ethanolic extract of Justicia adhatada and Calotropis gigantean leaves presented the inhibition zones against E.coli and S.aureus. Leaves of the two medicinal plants collected from in and around Lonar Lake forest were extracted with ethanol solvents to obtain crude extracts.
\end{abstract}

Key Words: Lonar Lake forest,Medicinal plants, Antimicrobial activity, Gram positive bacteria, Gram negative bacteria, Ethanol,Zone of Inhibition.

\section{Introduction}

Plants have been used as folk remedies and ethanobotanical literature has described the usage of plant extract, infusious and powders for centuries for diseases now known to be interic infection. Alkaline Lonar Lake rank third in the world based on its diameter with circular periphery and high alkalinity. The Lonar Lake is a part of Buldhana district of Maharashtra State ,India is the only hypervelocity meteoritic impact crater in basalt rock, The impact occurred about fifty thousand years ago and the resulting crater is a very impressive sight .This large impact crater has a mean diameter of $2 \mathrm{~km}$ (6600 feet) and adepth from the rins of $137 \mathrm{~m}(450$ Feet) In addition the crater has unique flora and fauna and is filled with saline water (Thakker and Ranade,2002 ) It has been well -known as an inland saline Soda Lake withhigh concentration of sodium carbonate and chloride (Kanekar etal.,2000 ). These the Lake is surrounded by the dense forest it preserves innumerable valuable medicinal plants with medicinal valuses and with rich alkaline angiospermic biodivdrsity (Malu etal.,2000).

The use of plants and products as medicines could be traced as far back as the beginning of human civilization.The earliest mention of medicinal use of plants in Hindu culture is found in "Rigceda",which is said to have been written between 4500-1600 B.C.and is supposed to be the oldest

repository of human knowledge. It is Ayurveda,the foundation of medicinal science of Hindu culture, in its eight division deals with specific properties of drugs and various aspects of science of life and the art of healing.(Rastogi and Mehrotra,2002)

Nature has been a source of medicinal agents for thousands of years and an impressive number of drugs have been isolated from natural resources. Herbal remedies play a vital role intraditional medicines in rural areas and found useful in gastrointestinal disorders (Neto etal ,2002)

The study of medicinal plants with a history of traditional use as a potential source of substances with significant pharmacological and biological activity .the Indian subcontinent is endowed with rich and diverse local health tradition, which is equally matched with rich and diverse plant genetic source a detailed investigationand documentation of medicinal plants used in local health traditions and ethanopharmacological 
evaluation to verify their efficacy and safety can lead to the development of invaluable herbal drugs or isolation of compounds of therapeutic value ( Vijayan etal,2003)

Lonar crater is a closed one without any out and unique due to its salinity, alkalinity and biodiversity .Due to the uniqueness, the crater has evoked much scientific values among researchers and continues to site of attraction for many water is the most vital abiotic component of the crater ecosystem and while studying the biodiversity of any crater ecosystem, the knowledge of medicinal plants around the crater the crater water is important these plants have medicinal potential and to valuate them for the betterment of human mankind . The important distinguishing feature of Ayurveda is that unlike other medical systems

Which developed their conceptual framework based on the results obtained with the use of drugs and therapy ,it first provided philosophical frame work that determined the therapeutic practice with good effects. This enabled it to evolve into radional system f medicine quite early in its evolution and to get detached from religious influence .It laid great emphasis on the value of evidence of senses and human reasoning. Systematic investigation was undertaken to screen the thimble and extracted successively with Ethanol local flora for antibacterial from solvent in Soxhlet extractor for $48 \mathrm{~h}$. The solvent extracts justicia adhatada,Calotropis gigantean were concentrated under reduced pressure. The at $5^{\circ} \mathrm{C}$ in airtight bottle until further use( Satish etal.,2010).plants are widely used for medicinal purpose in different countries and are a source of many potent and powerful drugs The interest in the scientific investigation of justicia adhatada,Calotropis gigantean is based on the claims of its effective use for the treatment of many diseases. The sap (latex) has antimicrobial activities against S. aureus and E.coli.Latex is used to dress sores, ulcers and inflamed tongues Therefore, this research regarding the antimicrobial activity of these plants are expected to enhance the uses of justicia adhatada,Calotropis gigantean against diseases ccausd by the test pathogens.it It is expected that screening of plant extract against wide variety of test organisms will be helpful in obtaining new antimicrobial substances (Sharma etal 2000 ). Herbal medicines are based on natural substances that can promote health and alleviate illness (Makhija etal., 2010 )

\section{Materials And Methods}

Collection Of Selected Medicinal Plants

Material - Selected medicinal plant material used for this study was collected from Lonar Lake forest. All the plants were idenfified at taxonomic section

\section{Preparation Of Solvent Extraction}

Preparation of plants extract thoroughly washed dried leaves of justicia adhatada,Calotropis gigantean selected two medicinal plants were tested by the disc diffusion bark extract of justicia adhatada and Calotropis gigantean by using solvent such as ethanol the solvent extract will be concertrated and preserved at $5 \mathrm{c}$ in air tight bottle until further use.

\section{Collection Of Test Organism}

The test organism were received from IMTECH, Chandigarh, India and reconfirmed by gram staining and sub culturing in appropriate seleative mediaGram positive bacteria and gram negative bacteria staphylococcus aureus and gram negative bacteria Escherichia coli were used as atestrgnisms test organisms

\section{Preparation Of Standard Culture Inoculums Of Test Organism}

A loopful of bacterial culture was inoculated in $10 \mathrm{ml}$ steril nutrient broth and incubated at $37^{\circ} \mathrm{C}$ till the growth in the broth was equivale with mac-Farland standard as recommended by who

\section{Determination Of Antimicrobial Activity}

filter paper disc methods was used for screening of crude extract for antimicrobial activity .standard size blank whatman filter paper dises,6.0 $0 \mathrm{~mm}$.in dimeter, sterilized by dry heat at 140c for 1 hour,were saturated with the extract and known quality of standard reference antibiotics separately .Now the discs were air dried at room temperature to remove any residual solvent which might interfere with the determination .The discs were then placed on the surface of the sterilized nutrient agar medium erile swab and air dried to remove moisture.that has been inoculated with the test organism by using sterile swab and air dried to remove moisture.

The thickness of the agar medium was kept equal in all petri plates and the standard discs of streptomycin were used seperatly for all microbes tested,in the petri plates as control. Before incubations ,petri plates were placed for $1 \mathrm{hrs}$ in a cold room to allow diffusion of the compounds from the disc into agar plate. These were incubated at 37c for $24 \mathrm{hrs}$, after which the zones of inhibition of desired growth could be easily measured. The zone of inhibition was considered as an indicator for the antimicrobial activity. At the end of the incubation period the antimicrobial activity was evaluated by measuring the inhibition zones. 
Considered as an indicator for the antimicrobial activity .At the end of the incubation period the antimicrobial activity was evaluated by measuring the inhibition zones

\begin{tabular}{|l|l|l|l|l|l|}
\hline \multicolumn{5}{|c|}{ Table I Ethnobotanical data of selected medicinal plants } \\
\hline Sr.No & Botanical Name & Local Name & Part used & Extract Prepared & Local Uses \\
\hline 1 & Justicia adhtoda & Adulsa & Leaves & Ethanol & Nasal infection,cough, Throat Infection \\
\hline 2 & Calotropis gigantea & Rui & Leaves & Ethanol & Boils, Elephanriasis,in wounds \\
\hline
\end{tabular}

\section{Results And Discussion}

The Leaves of two medicinal plants belonging to Different families used in the traditional system of medicinal plants collected from Lonar Lake forest were tested for their antibacterial activities.two plants extract from different families were found to have antibacterial activity against bacterial cultures. Most of these extracts have partial activity at the low concentration used in the preset study Justicia adhatoda showed better activity against E. coil in ethanol extracts and also found antibacterial activity aginst styaphilococcus ,auries Dhankar etal., (2011), reported that the alcoholic extract of leaves of Justicia adhatoda Showed antibacterial activity against $\mathrm{S}$ aureus and $\mathrm{E}$ coli aqueous extracts showed activity against $\mathrm{S}$ aureus, Calotropis gigantean showed antibacterial activity against E coli and S aureus with ethanol extract Murugan (2012) had reported that leaves $\&$ caltropis gigantean showed the antibacterial activity against E.coli .

Antimicrobial activity of Alcoholic Extracts of Different Medicinal plants against Different Pathogenic Microorganisms. The positive sign indicates that ethanol extract of particular medicinal plant can inhibit the growth of Microorganisms and thus zone of inhibition was produced which indicates that the plant has antimicrobial activity. The negative sign indicates that ethanol extract of particular medicinal plant cannot inhibit the growth of micro organism and cannot produce zone of inhibition.It indicates that plants have no antimicrobial activity.

\begin{tabular}{|l|l|l|l|l|}
\hline \multicolumn{3}{|c|}{ Table II : Zone of Inhibition ( mm ) of Extract of Selected Medicinal plants with Test Pathogens } \\
\hline Sr. No. & Plant Name & & Extract & Name of microorganisms \\
\cline { 3 - 5 } & & & S. aureus & E.coli \\
\hline 1 & Justicia adhatoda & Ethanol & $10(+)$ & $16(+)$ \\
\hline 2 & Calotropis gigantean & Ethanol & $12(+)$ \\
\hline
\end{tabular}

In the present study Justicia adhatoda showed maximum zone of inhibition(16 mm ) against E.coli in ethanol extract and no inhibition zone( - ) found in S.aureus in ethanol extract. Calotropis gigantean showed good zone of inhibition $(10 \mathrm{~mm})$ found in ethanol extract against S.aureus and $12 \mathrm{~mm}$ of zone of inhibition found in ethanol extract against E.coli .

Selected medicinal plants essential extract have been used for many thousands of years, in food preservation, pharmaceuticals, alternative medicine and natural therapies. It is necessary to Investigate those plants seientifically which have been used in traditional medicine to improve the quality of healthcare.plant extracts are potential sources of novel antimicrobial compounds especially against bacterial pathogens.In this work showed that the plant extracts inhibited bacterial growth but there effectiveness varied. The antimicrobial activity of many plant extracts has been previously reviewed and classified as strong, medium or weak. The medicinal plants justicia adhatada,Calotropis gigantean are being used traditionally for the treatment of Nasal infection, cough, Throat Infection, Boils, Elephantiasis, in wounds antibacterial activity has been attributed to the presence of some active constituents in the extract in conclusion, results of the present study support the folkloric usage of the studied plants and suggest that some of the plant extracts possess compounds with antimicrobial properties that can be further explored for antimicrobial activity. This antimicrobial study of the plant extracts demonstrated that folk medicine can be as effective as modern medicine to combat pathogenic microorganism.

\section{Conclusion}

On the basis of the present study results it was concluded that two selected medicial plants from the forest of Lonar Lake the medicial plants Showed the antibacterial activity against the bacterial pathogens The selected two medicinal plants the extracts possessing higer antibacterial effects should be further studied For their theraputic use as these plants are easily available, economically affordable and having medicinal values, hence these two medicinal plants can be used to minimize the common health problems and for achieving healthy life. 


\section{References}

[1]. Dhankar S,R Kaur, S Ruhil, M Balhara, S Dhankar and A K Chillar (2011), “A review on Justicia adgatoda : A Pontential Sorurce of Natural Medicine", African Journal of Plant Sciecce, Vol.5,No.11,pp.620-627.

[2]. Joshi B, Lekhak S, Sharma A, (2009), “Antibacterial properties of Medicinal Plant Ocimum sanctum Cinnamomum Zeylanicum Xanphoxylum armatum"

[3]. Kanekar P P,Nilegaonkar S S, Sarnaik S S and kellar A S (2000), “Optimization of Protease Activity of Alkaliphilic Bacteria Isolated From an Alkaline Lake in India”, Bio Resource Technol,Vol.85,No.1,pp.87-93.

[4]. Mahesh B, Satish S, (2008) "Antimicrobial Activity of some Important Medicinal Plant Against Plant and Human Pathogens", World Found of Agricultural Science 4 (S) pp.839-843.

[5]. Makhija I K,I P Sharma and D Khamar (2010), "Phytochemistry and Pharmacological Properties of Ficus riligiosa," Annals of Biological Research,vol.1,No.4,pp.171-180.

[6]. Malu RA, D S Dhabhade and M S Kodarkar (2000), "Diversity of Lonar Lake”, J. Aquet Bio, Vol. 15,pp.16-18

[7]. Murugan T (2012), "Antimicrobial Activity of Leaves and Latex Extract of the Herbal plant Calotropis gigantean", International Journal of Biology ,Pharmacy and Allied Science (IIBPAS), No.3,pp.261-270

[8]. Neto C C, C W Owens and R D Langfield (2002), “Antimicrobial Activity of Some Peruvian Medicinal Plants From the Collejian de Huayleas", J. Ethanopharmacol., Vol.79,pp.133-138

[9]. Rastogi, R.P., Mehrotra, B.N. (2002), “ Glossary of Indian Medicinal Plants”, National Institute of sceience communication, New Delhi, Ind

[10]. Thakker C D And D R Ranade (2002), “Alkalophilic Methanosarcina isolated from Lonar Lake”,Curr Sci, Vol.82,pp.445-458.

[11]. Vijayan P, Prashanth HC, Vijayaraj P, Dhanaraj SA, Badami S, Suresh B. (2003), "Hepatoprotective effect of the total alkaloid fraction of Solanum pseudocapsicum leaves". Pharm Biol, pp.41:443-8. 